\title{
Association between triglyceride-glucose index and risk of incident diabetes: a secondary analysis based on a Chinese cohort study
}

\author{
Xiaoli Li ${ }^{1,2}$, Guilong Li ${ }^{3}$, Tiantian Cheng ${ }^{2,4}$, Jing Liu' ${ }^{2}$, Guangyao Song ${ }^{1,2}$ and Huijuan Ma ${ }^{1,5^{*}}$ (D)
}

\begin{abstract}
Background: Recent studies have suggested the triglyceride-glucose index (TyG index) may serve as a suitable substitute for insulin resistance. However, evidence for the relationship between TyG index and risk of diabetes remains limited. This study sought to explore the association of baseline TyG index with risk of developing diabetes in Chinese adults.
\end{abstract}

Methods: This retrospective cohort study was conducted using data from the health screening program in China. A total of 201,298 non-diabetic individuals were included. TyG index was calculated as Ln [fasting plasma glucose $(\mathrm{mg} / \mathrm{dL}) \times$ fasting triglyceride level $(\mathrm{mg} / \mathrm{dL}) / 2$ ]. Diabetes was defined as fasting plasma glucose $\geq 126 \mathrm{mg} / \mathrm{dL}$ and/or self-reported diabetes. Cox proportion-hazard model was employed to evaluate the independent impact of baseline TyG index on future diabetes risk. Sensitivity and subgroup analyses were implemented to verify the reliability of results. Notably, data were downloaded from the DATADRYAD website, and used only for secondary analyses.

Results: During an average follow-up of 3.12 years, among 201,298 individuals aged $\geq 20$ years, 3389 subjects developed diabetes. After adjusting for potential confounders, elevated TyG index were independently correlated with greater risk of incident diabetes (hazard ratio (HR), 3.34; 95\% confidence interval (Cl), 3.11-3.60). Compared with the lowest quartile $(\mathrm{Q} 1)$, increasing TyG index $(\mathrm{Q} 2, \mathrm{Q} 3$, and $\mathrm{Q} 4)$ was related to increased HR estimates of incident diabetes [HR (95\% Cl), 1.83 (1.49-2.26); 3.29 (2.70-4.01), and 6.26 (5.15-7.60), respectively]. Moreover, a nonlinear relationship was observed between TyG index and risk of diabetes and the slope of the curve increased accompanying the rise of TyG index. Subgroup analysis revealed the positive association was stronger among subjects with age $<40$ years, body mass index $\geq 18.5 \mathrm{~kg} / \mathrm{m}^{2}$ and $<24 \mathrm{~kg} / \mathrm{m}^{2}$, or systolic blood pressure $<140 \mathrm{mmHg}$, or in females.

Conclusions: Elevated TyG index is independently correlated with increased risk of incident diabetes in Chinese adults, indicating it may represent a reliable predictor of diabetes in high-risk populations.

(Continued on next page)

\footnotetext{
* Correspondence: huijuanma76@163.com

'Department of Internal Medicine, Hebei Medical University, Shijiazhuang 050017, Hebei, China

${ }^{5}$ Hebei Key Laboratory of Metabolic Diseases, Hebei General Hospital, Shijiazhuang 050051, Hebei, China

Full list of author information is available at the end of the article
}

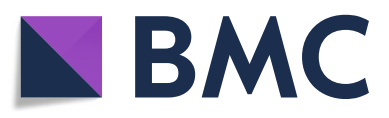

(c) The Author(s). 2020, corrected publication 2021. Open Access This article is licensed under a Creative Commons Attribution 4.0 International License, which permits use, sharing, adaptation, distribution and reproduction in any medium or format, as long as you give appropriate credit to the original author(s) and the source, provide a link to the Creative Commons licence, and indicate if changes were made. The images or other third party material in this article are included in the article's Creative Commons licence, unless indicated otherwise in a credit line to the material. If material is not included in the article's Creative Commons licence and your intended use is not permitted by statutory regulation or exceeds the permitted use, you will need to obtain permission directly from the copyright holder. To view a copy of this licence, visit http://creativecommons.org/ licenses/by/4.0/. The Creative Commons Public Domain Dedication waiver (http://creativecommons.org/publicdomain/zero/1. 0/) applies to the data made available in this article, unless otherwise stated in a credit line to the data. 
(Continued from previous page)

Keywords: Triglyceride-glucose index, Incident diabetes, Association, Nonlinearity, Insulin resistance, Cohort study, Chinese adults

\section{Background}

Diabetes has become an epidemic worldwide estimated to affect 439 million adults by 2030. It is a growing health problem imposing heavy financial burden on individuals and society [1-4]. To relieve this burden, public health strategies should focus on screening high-risk populations for incident diabetes, mainly for early prevention and appropriate intervention. Therefore, identification of a predictor that is easily measured, widely applicable, highly accurate, and especially easily intervened has important practical significance. Among various risk factors of diabetes, including metabolic, genetic and inflammatory risk factors, only some metabolic-related risk factors, such as dyslipidemia and high BMI, can be intervened through lifestyle changes [5-7].

Prospective studies have indicated insulin resistance (IR) remains the main pathogenesis of diabetes, which is present many years before diagnosis [8-10]. Clearly, accurate measurement of IR can improve the prediction of progression to diabetes. The hyperinsulinemic-euglycemic clamp (HIEC) technique continues to be the gold standard for quantitative IR [11], whereas it is costly and timeconsuming to apply in clinical practice. The triglycerideglucose index (TyG index), derived from triglyceride (TG) and fasting plasma glucose (FPG), was recommended as an alternative to IR in healthy subjects $[12,13]$ Several studies confirmed its accuracy for diagnosing IR, taking HIEC or homeostasis model assessment-IR (HOMA-IR) as reference standards [13-16]. Compared with insulinbased indices, the noninsulin-based TyG index is easily and inexpensively determined, which is advantageous in clinical and epidemiological research. Some studies revealed the TyG index was relevant with high risk of diabetes [17-20]. However, only one of the studies [17] was performed in China, with a relatively small sample size and individuals with normal body mass index (BMI), thereby limiting its generalizability. Therefore, the present study, based on a large cohort of 201,298 participants across 32 locations in 11 cities in China, sought to further explore the potential impact of baseline TyG index on future diabetes risk.

Remarkably, the original study was performed by Chen et al. [21], and the associated database was uploaded to the DATADRYAD website. The present report is a secondary analysis on the basis of the aforementioned database [21]. In the original study, the authors focused on the association of BMI with future diabetes risk [21]. In this secondary analysis, TyG index treated as independent variable, endpoint event and most covariates basically coincided with the original study.

\section{Methods}

\section{Data source}

Data were downloaded from the DATADRYAD website (www.datadryad.org), which allows others to freely obtain original data. In accordance with the Dryad Terms of Service, in this study, we refer to the following Dryad data package: Chen, Ying et al. (2018), data from: Association of body mass index and age with incident diabetes in Chinese adults: a population-based cohort study, Dataset, https://doi.org/10.5061/dryad.ft8750v. The following variables were involved in this database: sex, age, BMI, drinking, smoking, family history of diabetes, low density lipoprotein cholesterol (LDL-C), high density lipoprotein cholesterol (HDL-C), total cholesterol (TC), TG, FPG, serum creatinine (Scr), aspartate aminotransferase (AST), alanine aminotransferase (ALT), systolic blood pressure (SBP), diastolic blood pressure (DBP), FPG of final visit, incident diabetes at follow up and follow-up time. In the original paper [21], the authors declared that they have relinquished copyright and relevant ownership of the database. Thus, this database can be used for secondary analyses without violating the authors' rights.

\section{Study population}

Chen et al. performed the original study [21]. Here is a brief summary of their study protocol, the complete details of which are previously described [21]. The authors conducted a retrospective cohort study across 32 locations in 11 cities in China using data from a health screening project established by the Rich Healthcare Group. They recruited 685,277 participants who underwent at least two health checks between 2010 and 2016 . Ultimately, 211,833 participants were enrolled according to eligibility criteria, and exclusive criteria included: (1) baseline height, weight, sex, or FPG were unavailable; (2) outliers of BMI $\left(<15 \mathrm{~kg} / \mathrm{m}^{2}\right.$ or $\left.>55 \mathrm{~kg} / \mathrm{m}^{2}\right)$; (3) follow-up interval was less than 2 years; and (4) participants had diabetes at baseline or the status of diabetes was undefined at the deadline. Additionally, in the original article [21], Chen et al. declared the research was authorized by the Rich Healthcare Group Review Board. They only retrieved data retrospectively, and no subjects were required to participate in any part of the study, so the informed consent of participants were not involved in 
the study. In this report, some data were removed from the analysis cohort for further study: (1) missing TG values at baseline $(n=5747)$; and (2) extreme TG or FPG values (< mean -3 standard deviations (SD) or > mean $+3 \mathrm{SD})(n=4789)$ [22]. In total, 201,298 subjects $(109,236$ males and 92,062 females) were included for analysis in this study.

\section{Measurement of the TyG index and other covariates}

A detailed questionnaire was administered to obtain demographic characteristics, lifestyle, disease history, and medical history. Height measurement was accurate to $0.1 \mathrm{~cm}$. When measuring weight (accurate to $0.1 \mathrm{~kg}$ ), subjects were required to wear lightweight and no shoes. BMI was calculated as weight / height squared $\left(\mathrm{kg} / \mathrm{m}^{2}\right)$. Fasting venous blood was drawn to detect serum LDLC, TG, TC, HDL-C and FPG values by an automatic biochemical analyzer (Beckman 5800). The TyG index was calculated as Ln [FPG $(\mathrm{mg} / \mathrm{dL}) \times$ fasting TG $(\mathrm{mg} / \mathrm{dL}) / 2$ ] [12]. Because this was a retrospective cohort study, observation bias was naturally reduced.

\section{Ascertainment of diabetes}

Diabetes was defined according to FPG $\geq 126 \mathrm{mg} / \mathrm{dL}$ or self-reported diabetes. Ascertainment of diabetes depended on the date of diagnosis or the last visit.

\section{Statistical analysis}

The missing values of other variables were first supplemented before statistical analysis. If the missing values were continuous variables (such as TC, LDL-C, ALT, AST, Scr, SBP and DBP), they were supplemented by the mean or median. When missing data were categorical variables (such as smoking and drinking status), they were treated as a set of categorical variables [23].

Data for qualitative variables are expressed as numbers (percentage), while data for quantitative variables are shown as median (25th-75th percentile) or mean \pm SD. The statistical differences of percentage, median and mean among groups were verified by chi-square test, Kruskal-Wallis $\mathrm{H}$ test and one-way ANOVA, respectively. Cox proportional hazard model was used for evaluating the independent impact of TyG index on diabetes risk. In addition to the unadjusted model, results for the minor adjustment model (model I) and full adjustment model (model II) were presented. Taking TyG index as a categorical variable, sensitivity analysis was implemented to test the robustness of results. Additionally, a generalized additive model was employed to analyse the nonlinear relationship of TyG index with risk of diabetes. Subgroup analyses were implemented to further verify the robustness of the results. Furthermore, the likelihood ratio test was conducted to evaluate the interaction among subgroups. The Kaplan-Meier curve was used for generating cumulative event rates and the log-rank test was applied to compare outcome events distributions among groups.

Statistical analyses were carried on using $\mathrm{R}$ statistical software packages (http://www.r-project.org, The R Foundation) and EmpowerStats (http://www.empowerstats.com, X\&Y Solutions, Inc., Boston, MA). A two-sided $P$-value $<0.05$ was considered significant.

\section{Results \\ Population selection}

Of the 211,833 participants, 5746 were excluded for lack of baseline TG values, while 4789 were excluded because of extreme TG or FPG values, leaving 201,298 subjects for final data analysis.

\section{Baseline parameters of study population}

A total of 201,298 subjects $(54.3 \%$ male and $45.7 \%$ female) were involved in this study. Average age and BMI of the population were $42.08 \pm 12.67$ years and $23.19 \pm$ $3.32 \mathrm{~kg} / \mathrm{m}^{2}$, respectively. After an average follow-up of 3.12 years (SD, 0.94), 3389 participants were reported to have diabetes. The average TyG index was $8.35 \pm 0.57$, and baseline TyG index in diabetic patients was obviously higher than subjects without diabetes $(8.90 \pm 0.52$ vs. $8.34 \pm 0.57 ; p<0.001)$. Table 1 displayed baseline parameters of the population by TyG index quartiles (<7.93, 7.93-8.31, 8.31-8.73, $\geq 8.73$ ). Except for HDL$\mathrm{C}$, which was not statistically different among the TyG quartiles, participants with higher TyG index generally had higher age, BMI, LDL-C, TC, ALT, AST, Scr, SBP, DBP, family history of diabetes, higher rates of smokers and drinkers.

\section{Univariate analysis}

The univariate analyses of potential risk factors were presented in Table 2. The results revealed that these factors, including age, BMI, LDL-C, TC, TG, FPG, TyG index, ALT, AST, Scr, SBP, DBP, drinking, smoking and family history of diabetes, were positively related to future risk of diabetes, whereas HDL-C was not correlated with future risk. Besides, compared with males, females showed a lower risk of diabetes.

As shown in Fig. 1, Kaplan-Meier curve revealed that the cumulative risk of incident diabetes was markedly different among the TyG index quartiles (log-rank test, $P<0.001)$ and increased gradually with increase of TyG index, resulting in maximum risk of diabetes in the highest quartile.

Relationship between TyG index and future diabetes risk As shown in Table 3, the effect of TyG index on risk of diabetes was assessed by cox proportional hazard 
Table 1 Baseline parameters of population $(N=201,298)$

\begin{tabular}{|c|c|c|c|c|c|}
\hline TyG index & Q1 $(<7.93)$ & Q2 $(\geq 7.93$ to $<8.31)$ & Q3 $(\geq 8.31$ to $<8.73)$ & Q4 ( $\geq 8.73)$ & $P$-value \\
\hline Participants & 49,413 & 50,766 & 49,852 & 51,267 & \\
\hline Age (years, mean $\pm S D$ ) & $37.32 \pm 9.93$ & $40.48 \pm 12.00$ & $43.76 \pm 13.26$ & $46.61 \pm 13.20$ & $<0.001$ \\
\hline Sex, n (\%). & & & & & $<0.001$ \\
\hline Male & $16,016(32.41)$ & 24,391 (48.05) & $30,683(61.55)$ & $38,146(74.41)$ & \\
\hline Female & $33,397(67.59)$ & $26,375(51.95)$ & $19,169(38.45)$ & $13,121(25.59)$ & \\
\hline $\mathrm{BMI}\left(\mathrm{kg} / \mathrm{m}^{2}\right.$, mean $\left.\pm \mathrm{SD}\right)$ & $21.26 \pm 2.59$ & $22.40 \pm 2.95$ & $23.71 \pm 3.13$ & $25.31 \pm 3.11$ & $<0.001$ \\
\hline $\mathrm{SBP}(\mathrm{mmHg}$, mean $\pm \mathrm{SD})$ & $112.37 \pm 14.02$ & $116.50 \pm 15.29$ & $120.82 \pm 16.07$ & $125.62 \pm 16.64$ & $<0.001$ \\
\hline $\mathrm{DBP}(\mathrm{mmHg}$, mean $\pm \mathrm{SD})$ & $69.98 \pm 9.53$ & $72.45 \pm 10.09$ & $75.10 \pm 10.51$ & $78.47 \pm 10.92$ & $<0.001$ \\
\hline $\mathrm{FPG}(\mathrm{mg} / \mathrm{dL}$, mean $\pm \mathrm{SD})$ & $83.49 \pm 9.29$ & $86.88 \pm 9.40$ & $89.61 \pm 9.75$ & $93.58 \pm 10.48$ & $<0.001$ \\
\hline $\mathrm{TC}(\mathrm{mg} / \mathrm{dL}$, mean $\pm \mathrm{SD})$ & $165.41 \pm 28.64$ & $175.71 \pm 30.75$ & $185.95 \pm 32.89$ & $198.45 \pm 34.94$ & $<0.001$ \\
\hline $\mathrm{TG}(\mathrm{mg} / \mathrm{dL}$, mean $\pm \mathrm{SD})$ & $51.00 \pm 11.26$ & $78.87 \pm 12.03$ & $113.51 \pm 18.14$ & $199.82 \pm 58.97$ & $<0.001$ \\
\hline $\mathrm{LDL}-\mathrm{C}(\mathrm{mg} / \mathrm{dL}$, mean $\pm \mathrm{SD})$ & $79.28 \pm 22.93$ & $85.06 \pm 27.52$ & $90.81 \pm 31.54$ & $95.18 \pm 34.56$ & $<0.001$ \\
\hline $\mathrm{HDL}-\mathrm{C}(\mathrm{mg} / \mathrm{dL}$, mean $\pm \mathrm{SD})$ & $53.17 \pm 11.91$ & $53.09 \pm 11.82$ & $53.08 \pm 11.90$ & $53.07 \pm 11.79$ & 0.769 \\
\hline ALT (IU/L, median (Q1-Q3) & $13.90(10.90-18.60)$ & 16.00 (12.00-22.80) & 19.05 (14.00-28.00) & $25.40(18.00-38.30)$ & $<0.001$ \\
\hline $\mathrm{AST}(\mathrm{IU} / \mathrm{L}$, mean $\pm \mathrm{SD})$ & $21.74 \pm 6.05$ & $22.25 \pm 6.41$ & $22.95 \pm 6.75$ & $24.25 \pm 8.22$ & $<0.001$ \\
\hline $\mathrm{Scr}(\mathrm{mg} / \mathrm{dL}$, mean $\pm \mathrm{SD})$ & $0.73 \pm 0.15$ & $0.77 \pm 0.16$ & $0.81 \pm 0.16$ & $0.84 \pm 0.16$ & $<0.001$ \\
\hline Smoker & & & & & $<0.001$ \\
\hline Now & $1011(2.05)$ & $2096(4.13)$ & $3140(6.30)$ & $4824(9.41)$ & \\
\hline Once & $304(0.62)$ & $536(1.06)$ & $732(1.47)$ & $847(1.65)$ & \\
\hline Never & $10,591(21.43)$ & $11,372(22.40)$ & $10,978(22.02)$ & $10,556(20.59)$ & \\
\hline Not recorded & $37,507(75.90)$ & $36,762(72.41)$ & $35,002(70.21)$ & $35,040(68.35)$ & \\
\hline Drinker & & & & & $<0.001$ \\
\hline Now & $108(0.22)$ & $225(0.44)$ & $329(0.66)$ & $581(1.13)$ & \\
\hline Once & $1180(2.39)$ & $1831(3.61)$ & $2357(4.73)$ & $3128(6.10)$ & \\
\hline Never & $10,618(21.48)$ & $11,948(23.54)$ & $12,164(24.40)$ & $12,518(24.42)$ & \\
\hline Not recorded & $37,507(75.91)$ & $36,762(72.41)$ & $35,002(70.21)$ & $35,040(68.35)$ & \\
\hline Family history of diabetes, $\mathrm{n}(\%)$ & & & & & $<0.001$ \\
\hline No & $48,526(98.20)$ & 49,708 (97.92) & $48,804(97.90)$ & $50,158(97.84)$ & \\
\hline Yes & $887(1.80)$ & $1058(2.08)$ & $1048(2.10)$ & $1109(2.16)$ & \\
\hline
\end{tabular}

Values are presented as mean $\pm \mathrm{SD}$, median (Q1-Q3) or $\mathrm{n}(\%)$

$B M I$ Body-mass index, SBP Systolic blood pressure, DBP Diastolic blood pressure, FPG Fasting plasma glucose, TC Total cholesterol, TG Triglyceride, LDL-C Lowdensity lipoprotein cholesterol, HDL-C High-density lipoprotein cholesterol, ALT Alanine aminotransferase, AST Aspartate transaminase, Scr Serum creatinine

model. In crude model, TyG index demonstrated a strongly positive association with future diabetes risk (HR, 5.78; 95\% CI, 5.44-6.14). In model I (adjusted for sex, age and BMI), the positive correlation became relatively weaker ( $\mathrm{HR}, 3.31 ; 95 \% \mathrm{CI}, 3.09-3.55)$. In model II (further adjusted for TC, LDL-C, AST, ALT, Scr, DBP, SBP, drinking, smoking and family history of diabetes), the correlation did not change significantly compared with the minor adjustment model (HR, 3.34; 95\% CI, 3.11-3.60).

To ensure the robustness of the results, TyG index was processed a categorical variable (quartiles) for sensitivity analysis. There was a graded and positive correlation of TyG index with future risk of diabetes. Compared with the lowest quartile (Q1), increasing TyG index (Q2, Q3, and Q4) was related to increased HR estimates of incident diabetes [HR (95\% CI), 1.83 (1.49$2.26) ; \quad 3.29(2.70-4.01)$ and $6.26 \quad(5.15-7.60)$, respectively].

\section{Nonlinear relationship}

As shown in Fig. 2, after adjusting for sex, age, BMI, LDL-C, TC, ALT, AST, Scr, SBP, DBP, smoking, drinking, and family history of diabetes, a significant nonlinear relationship was found between TyG index and risk of future diabetes $(P<0.001)$, and the slope of the curve 
Table $\mathbf{2}$ The results of univariate analysis

\begin{tabular}{|c|c|c|c|}
\hline & Statistics & HR $(95 \% \mathrm{Cl})$ & $P$ value \\
\hline Age (y) & $42.08 \pm 12.67$ & $1.07(1.06-1.07)$ & $<0.0001$ \\
\hline \multicolumn{4}{|l|}{ Gender } \\
\hline Male & $109,236(54.27 \%)$ & Ref & \\
\hline Female & 92,062 (45.73\%) & $0.51(0.47-0.55)$ & $<0.0001$ \\
\hline BMI $\left(\mathrm{kg} / \mathrm{m}^{2}\right)$ & $23.19 \pm 3.32$ & $1.24(1.23-1.25)$ & $<0.0001$ \\
\hline $\mathrm{SBP}(\mathrm{mmHg})$ & $118.88 \pm 16.31$ & $1.04(1.04-1.04)$ & $<0.0001$ \\
\hline $\mathrm{DBP}(\mathrm{mmHg})$ & $74.03 \pm 10.76$ & $1.05(1.04-1.05)$ & $<0.0001$ \\
\hline LDL-C (mg/dL) & $87.64 \pm 30.11$ & $1.01(1.00-1.02)$ & $<0.0001$ \\
\hline $\mathrm{HDL}-\mathrm{C}(\mathrm{mg} / \mathrm{dL})$ & $53.10 \pm 11.85$ & $1.00(1.00-1.01)$ & 0.4881 \\
\hline $\mathrm{TC}(\mathrm{mg} / \mathrm{dL})$ & $181.51 \pm 34.19$ & $1.01(1.01-1.01)$ & $<0.0001$ \\
\hline $\mathrm{TG}(\mathrm{mg} / \mathrm{dL})$ & $111.41 \pm 64.72$ & $1.01(1.01-1.01)$ & $<0.0001$ \\
\hline $\mathrm{FPG}(\mathrm{mg} / \mathrm{dL})$ & $88.43 \pm 10.43$ & $1.15(1.14-1.15)$ & $<0.0001$ \\
\hline TyG index & $8.35 \pm 0.57$ & $5.78(5.44-6.14)$ & $<0.0001$ \\
\hline $\mathrm{Scr}(\mathrm{mg} / \mathrm{dL})$ & $0.79 \pm 0.17$ & $2.87(2.34,3.52)$ & $<0.0001$ \\
\hline $\operatorname{ALT}(\mathrm{U} / \mathrm{L})$ & $23.52 \pm 19.95$ & $1.01(1.01-1.01)$ & $<0.0001$ \\
\hline AST (U/L) & $22.81 \pm 6.98$ & $1.01(1.01-1.02)$ & $<0.0001$ \\
\hline \multicolumn{4}{|l|}{ Smoker } \\
\hline Now & $11,071(5.50 \%)$ & Ref & \\
\hline Once & $2419(1.20 \%)$ & $0.75(0.56-1.00)$ & 0.0506 \\
\hline Never & 43,497 (21.61\%) & $0.46(0.40-0.53)$ & $<0.0001$ \\
\hline Not recorded & $144,311(71.69 \%)$ & $0.63(0.56-0.71)$ & $<0.0001$ \\
\hline \multicolumn{4}{|l|}{ Drinker } \\
\hline Now & $1243(0.62 \%)$ & Ref & \\
\hline Once & 8496 (4.22\%) & $0.48(0.33-0.70)$ & 0.0001 \\
\hline Never & 47,248 (23.47\%) & $0.50(0.35-0.70)$ & $<0.0001$ \\
\hline Not recorded & 144,311 (71.69\%) & $0.54(0.39-0.76)$ & 0.0003 \\
\hline \multicolumn{4}{|c|}{ Family history of diabetes } \\
\hline No & $197,196(97.96 \%)$ & Ref & \\
\hline Yes & $4102(2.04 \%)$ & $1.74(1.47-2.06)$ & $<0.0001$ \\
\hline \multicolumn{4}{|c|}{$\begin{array}{l}\text { Data were expressed as mean } \pm \text { SD or } n(\%) \\
B M I \text { Body-mass index, SBP Systolic blood pressure, DBP Diastolic blood } \\
\text { pressure, TC Total cholesterol, } T G \text { Triglyceride, } L D L-C \text { Low-density lipoprotein } \\
\text { cholesterol, HDL-C High-density lipoprotein cholesterol, FPG Fasting plasma } \\
\text { glucose, TyG index triglyceride-glucose index, Scr Serum creatinine, ALT Alanine } \\
\text { aminotransferase, AST Aspartate transaminase }\end{array}$} \\
\hline
\end{tabular}

showed an upward tendency with the increase of TyG index.

\section{Subgroup analysis}

To further investigate the impact of other risk factors on the correlation of TyG index with future diabetes risk, subgroup analyses were carried on according to the following stratification variables: sex, age, BMI, DBP, SBP, smoking, drinking and family history of diabetes. The results of subgroup analyses and interactions were summarized in Table 4. The additive interactions between TyG index and diabetes risk were observed in sex, age, BMI, and SBP $(P$-value for interaction $<0.05)$. Stronger correlations were found in participants with age $<40$ years, BMI $\geq 18.5 \mathrm{~kg} / \mathrm{m}^{2}$ and $<24 \mathrm{~kg} / \mathrm{m}^{2}$, or SBP $<140 \mathrm{mmHg}$, or in females. However, significant interactions were not found in DBP, smoking, drinking, or family history of diabetes.

\section{Discussion}

This retrospective cohort study revealed that raised TyG index was independently correlated with greater risk of developing diabetes among apparently healthy adults in China (HR, 3.34; 95\% CI, 3.11-3.60). Besides, a significant nonlinear relationship was observed and showed the risk of diabetes tend to ascend with increase of TyG index. Compared with the lowest quartile, individuals with the top quartile of TyG index demonstrated a sixfold greater risk of developing diabetes (Q4 vs. Q1; adjusted HR 6.26, 95\% CI 5.15-7.60). Additionally, the results of subgroup analysis revealed this correlation existed regardless of participants being male or female, younger or older, or obese or nonobese, suggesting our results were robust and the TyG index was suitable for a wide range of subjects. Moreover, stronger associations were observed in participants with age $<40$ years, $\mathrm{BMI} \geq$ $18.5 \mathrm{~kg} / \mathrm{m}^{2}$ and $<24 \mathrm{~kg} / \mathrm{m}^{2}$, or $\mathrm{SBP}<140 \mathrm{mmHg}$, or in females.

The TyG index, derived from FPG and TG, was proven as a marker of IR in many epidemiological studies $[12-16,24]$. Compared with HIEC, the TyG index had high sensitivity (96.5\%) as well as good specificity (85.0\%) for diagnosing IR in a Mexican population [13], and was a more accurate predictor than HOMA-IR in a Brazilian study [14]. Moreover, consistent with this study, several studies suggested that high TyG index was relevant to future risk of T2DM in different races, as shown in reports from Korea, Singapore, and Europe [18-20, 25]. Similar results were observed in another Chinese cohort study [17] and the trend of nonlinear relationship of TyG index with diabetes risk was generally consistent with our study. However, the study only included 5706 subjects with normal BMI and was conducted in rural areas. Therefore, its generalizability is relatively limited. This study was based on a large cohort of 201,298 apparently healthy adults across 32 sites in 11 cities, and is clearly applicable to a relatively wide range of individuals, and provides a stronger basis for clinical promotion and application. Similarly, the risk of diabetes in a Singaporean population elevated progressively across TyG index quartiles $(\mathrm{Q})$ from $\mathrm{Q} 1$ to $\mathrm{Q} 4(\mathrm{Q} 4 \mathrm{vs}$. Q1; adjusted HR 5.30, 95\% CI 2.21-12.71) [20]. However, potential confounders, such as serum lipid index (LDL-C and TC), drinking, smoking and family history of diabetes, were not sufficiently adjusted, and were notablely relevant to high risk of diabetes [26-31]. 


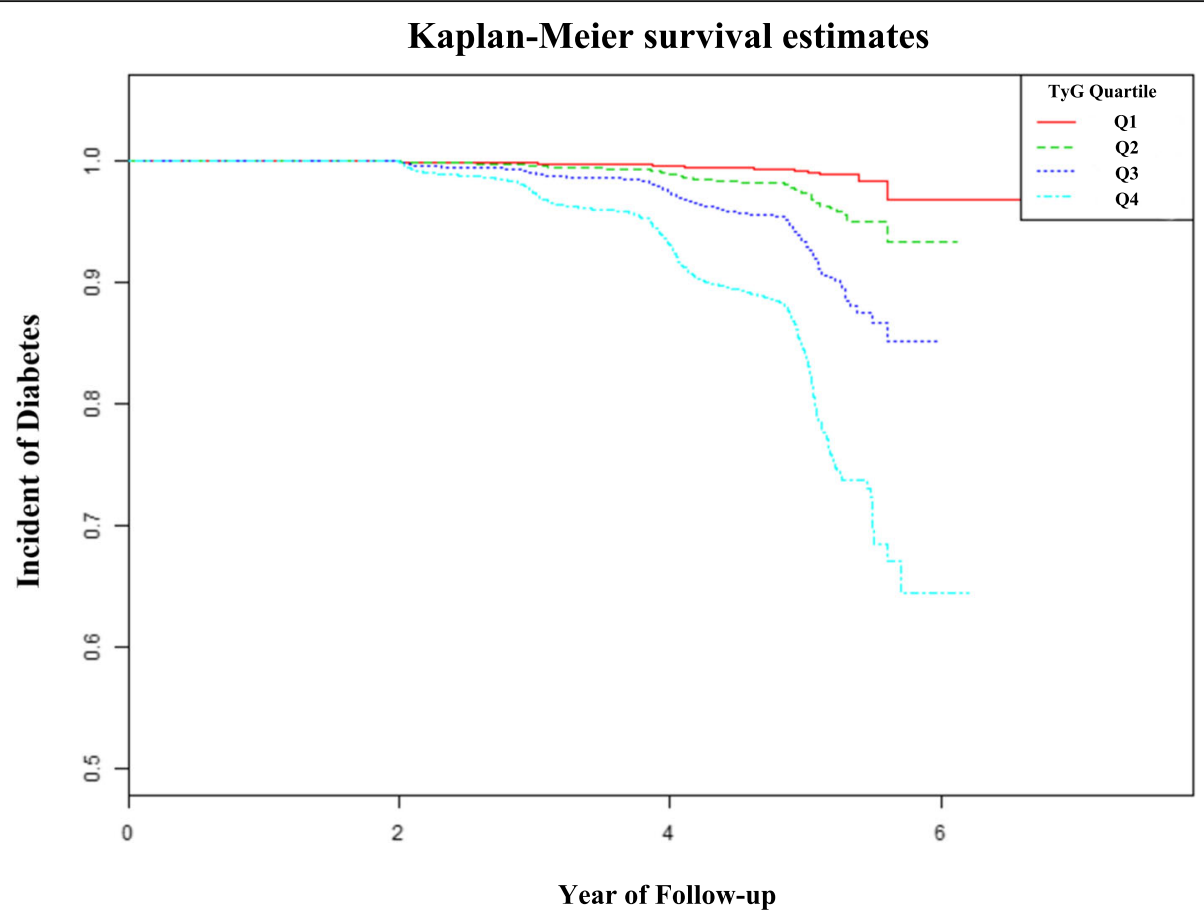

Fig. 1 Kaplan-Meier analysis of future diabetes risk according to TyG index quartiles (log-rank, $P<0.0001$ )

Fortunately, these confounding factors were taken into consideration in this study to avoid potential effects on the results.

Islet $\beta$-cell dysfunction and IR remain the core pathological trait of T2DM [32]. Interestingly, the TyG index, besides being a substitute of IR, is associated with susceptibility of $\beta$-cells to glucotoxicity and lipotoxicity. Pancreatic $\beta$-cells show weak antioxidant enzyme defense, and oxidative stress has been proved to be an important feature for the pathogenesis and development of type 2 diabetes (T2DM) [33-35]. Besides, some indirect evidence also suggested that appropriate antioxidant supplementation can regulate lipid metabolism and improve insulin sensitivity [36-38]. Evidence suggested that elevated glucose levels can induce reactive oxygen species generation on islet $\beta$-cells, which in turn cause oxidative stress and $\beta$-cells dysfunction, and then lead to IR and T2DM [33-35]. Other studies revealed that longterm high free fatty acid content was related to prolonged exposure of TG in pancreatic islets, which may impair pancreatic $\beta$-cell function [39-41]. Furthermore, glycotoxicity and lipotoxicity were interactive rather than independent adverse effects on pancreatic $\beta$-cell [42-44]. Long term exposure of pancreatic beta cells to high fatty acids concentrations could result in impaired glucose-induced insulin secretion $[45,46]$ and increased

Table 3 Relationship between TyG index and risk of diabetes

\begin{tabular}{|c|c|c|c|c|c|c|}
\hline \multirow[t]{2}{*}{ Outcomes } & \multicolumn{2}{|l|}{ Crude model } & \multicolumn{2}{|l|}{ Model I } & \multicolumn{2}{|l|}{ Model II } \\
\hline & HR (95\% CI) & $P$ & HR (95\% Cl) & $P$ & HR $(95 \% \mathrm{Cl})$ & $P$ \\
\hline TyG index & $5.78(5.44-6.14)$ & $<0.0001$ & $3.31(3.09-3.55)$ & $<0.0001$ & $3.34(3.11-3.60)$ & $<0.0001$ \\
\hline \multicolumn{7}{|c|}{ TyG (quartile) } \\
\hline Q 1 & Ref & & Ref & & Ref & \\
\hline Q 2 & $2.88(2.34-3.53)$ & $<0.0001$ & $1.84(1.50-2.27)$ & $<0.0001$ & $1.83(1.49-2.26)$ & 0.0293 \\
\hline Q 3 & 7.45 (6.17-9.00) & $<0.0001$ & $3.29(2.70-3.99)$ & $<0.0001$ & $3.29(2.70-4.01)$ & 0.0004 \\
\hline Q 4 & $19.94(16.64-23.88)$ & $<0.0001$ & $6.36(5.26-7.70)$ & $<0.0001$ & $6.26(5.15-7.60)$ & $<0.0001$ \\
\hline $\mathrm{P}$ for trend & $<0.0001$ & & $<0.0001$ & & $<0.0001$ & \\
\hline
\end{tabular}

Crude model: adjusted for none

Model I: adjusted for age, sex and BMI

Model II: adjusted for age, sex, BMI, LDL-C, TC, Scr, AST, ALT, SBP, DBP, drinking, smoking and family history of diabetes 


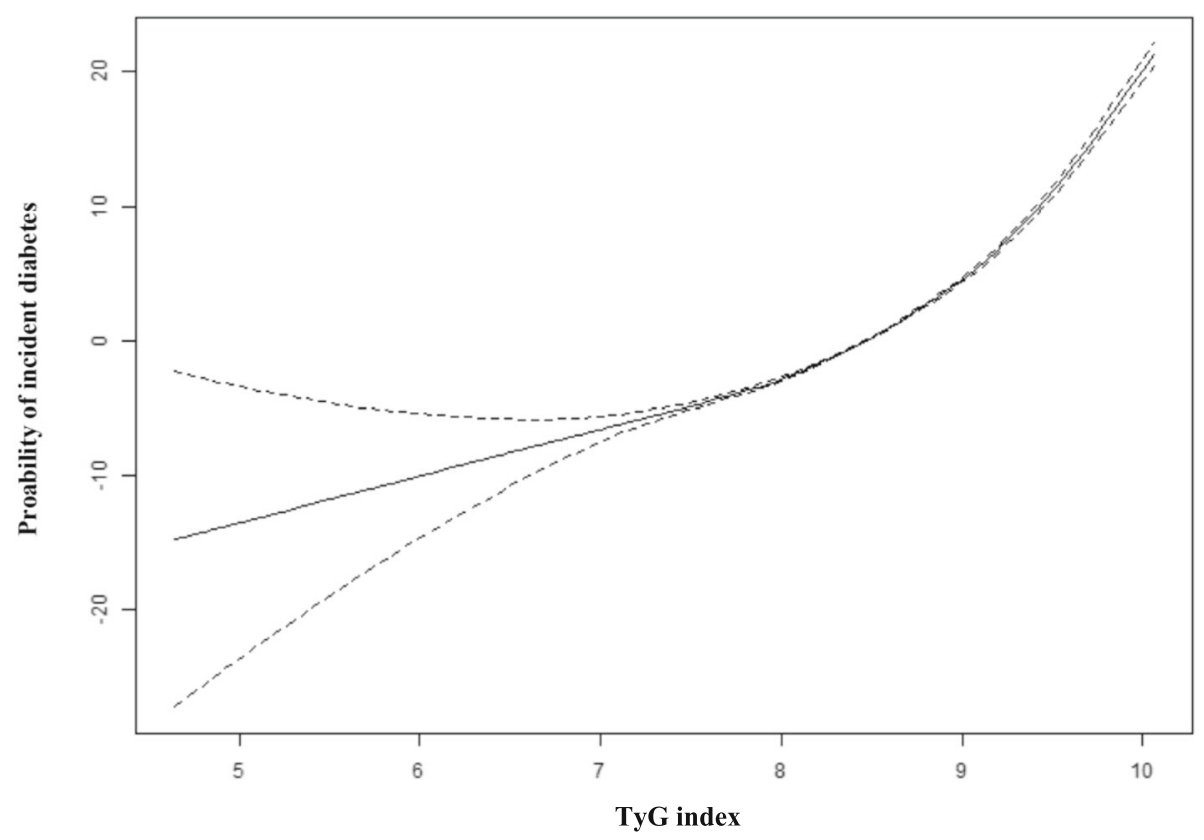

Fig. 2 A nonlinear relationship of TyG index with risk of future diabetes. Note: the model was adjusted for sex, age, BMI, AST, ALT, LDL-C, TC, SCr, SBP, DBP, drinking, smoking and family history of diabetes

$\beta$-cell death [47]. An intervention study confirmed that patients with impaired glucose metabolism had improved insulin secretion ability after being treated with n-3 fatty acids [48]. Besides, IR is largely attributable to the impairment of insulin-stimulated glucose absorption into skeletal muscle. When TG levels in peripheral blood and skeletal muscle were significantly increased, glucose metabolism in skeletal muscle would be impaired [49]. Therefore, to a certain extent, the TyG index reflects muscle IR [50].

Subgroup analysis and exploration of interactions is critical for clinical research, to better understand the actual relationships between independent variables and dependent variables [51]. Unfortunately, the related studies described above only used sex, and/or age as stratification factors for subgroup analyses [17-19], and no interactions were observed, which may hinder our understanding of the real association of TyG index with future diabetes risk. In this study, these factors, including BMI, sex, age, DBP, SBP, drinking, smoking and family history of diabetes, were taken as stratified variables, and stronger associations were observed in participants with age $<40$ years, BMI $\geq 18.5 \mathrm{~kg} / \mathrm{m}^{2}$ and $<24 \mathrm{~kg} /$ $\mathrm{m}^{2}$, or SBP $<140 \mathrm{mmHg}$, or in females. This association was particularly obvious in females, and was consistent with the cohort study by Zhang et al. [17]. This may be because serum lipids in female hepatocytes were higher than that in male hepatocytes under fasting and glucose lipid loading [52, 53]. In clinical practice, lean and obese individuals are not homogeneous, and obese individuals are generally considered more likely to develop diabetes. However, in the subgroup analysis based on BMI, regardless of lean individuals $\left(\mathrm{BMI}<18.5 \mathrm{~kg} / \mathrm{m}^{2}\right)$ or obese individuals (BMI $>32 \mathrm{~kg} / \mathrm{m}^{2}$ ), TyG index demonstrated a strongly positive association with future diabetes risk in this study $\left[\left(\mathrm{BMI}<18.5 \mathrm{~kg} / \mathrm{m}^{2}, \mathrm{HR}(95 \% \mathrm{CI})\right.\right.$, 3.64 (1.53-8.64); and BMI $\geq 32 \mathrm{~kg} / \mathrm{m}^{2}$, HR (95\% CI), 3.36 (2.33-4.85); respectively)]. The possible explanation for this result was that the mechanism of TyG index mediating diabetes in different BMI populations might be different. High TyG index, in obese individuals, may increase the risk of diabetes mainly by increasing insulin resistance, while in lean individuals mainly by damaging $\beta$-cells through glycotoxicity and lipotoxicity. On the whole, based on subgroup analysis, the TyG index appeared to be more sensitive for predicting risk of diabetes in younger individuals and those with normal BMI or SBP, suggesting it may be promising for screening risk of future diabetes, especially in individuals without high-risk factors such as hypertension, obesity and older age.

\section{Study strengths and limitations}

This study had several advantages. First, it was based on a large sample cohort study with broad age spectrum. Therefore, there were sufficient subjects for analysis to guarantee dependability and robustness of results. Furthermore, the results are applicable to a relatively wide range of individuals. Other similar cohort studies had relatively small sample sizes and populations that tended 
Table 4 Effect of magnitude of TyG index on diabetes risk stratified by subgroups

\begin{tabular}{|c|c|c|c|c|}
\hline Characteristics & No. of participants & HR $(95 \% \mathrm{Cl})$ & $P$-value & $P$ for interaction \\
\hline Age (year) & & & & $<0.0001$ \\
\hline$<40$ & 106,447 & $4.53(3.76-5.45)$ & $<0.0001$ & \\
\hline$>=40,<60$ & 71,176 & 3.54 (3.19-3.93) & $<0.0001$ & \\
\hline$>=60$ & 23,675 & $2.67(2.37-3.00)$ & $<0.0001$ & \\
\hline Sex & & & & 0.0150 \\
\hline Male & 109,236 & $3.16(2.90-3.45)$ & $<0.0001$ & \\
\hline Female & 92,062 & $3.84(3.37-4.37)$ & $<0.0001$ & \\
\hline BMI $\left(\mathrm{kg} / \mathrm{m}^{2}\right)$ & & & & 0.0075 \\
\hline$<18.5$ & 11,593 & $3.64(1.53-8.64)$ & 0.0034 & \\
\hline$>=18.5,<24$ & 112,241 & $4.13(3.62-4.71)$ & $<0.0001$ & \\
\hline$>=24,<28$ & 60,886 & $3.22(2.90-3.58)$ & $<0.0001$ & \\
\hline$>=28,<32$ & 14,388 & $3.11(2.64,3.68)$ & $<0.0001$ & \\
\hline$>=32$ & 2190 & $3.36(2.33,4.85)$ & $<0.0001$ & \\
\hline $\mathrm{SBP}(\mathrm{mmHg})$ & & & & $<0.0001$ \\
\hline$<140$ & 181,383 & $3.48(3.19-3.79)$ & $<0.0001$ & \\
\hline$>=140$ & 19,915 & $2.89(2.53-3.29)$ & $<0.0001$ & \\
\hline $\mathrm{DBP}(\mathrm{mmHg})$ & & & & 0.9984 \\
\hline$<90$ & 185,636 & $3.29(3.04-3.56)$ & $<0.0001$ & \\
\hline$>=90$ & 15,661 & $3.43(2.90-4.05)$ & $<0.0001$ & \\
\hline Smoker & & & & 0.6979 \\
\hline Now & 11,071 & $3.03(2.36-3.90)$ & $<0.0001$ & \\
\hline Once & 2419 & $4.27(2.30-7.91)$ & $<0.0001$ & \\
\hline Never & 43,497 & $3.40(2.84-4.08)$ & $<0.0001$ & \\
\hline Not recorded & 144,311 & $3.39(3.13-3.69)$ & $<0.0001$ & \\
\hline Drinker & & & & 0.2174 \\
\hline Now & 1243 & $5.31(2.34-12.05)$ & $<0.0001$ & \\
\hline Once & 8496 & $3.65(2.52-5.28)$ & $<0.0001$ & \\
\hline Never & 47,248 & $3.33(2.84-3.90)$ & $<0.0001$ & \\
\hline Not recorded & 144,311 & $3.39(3.13-3.69)$ & $<0.0001$ & \\
\hline Family history of diabetes & & & & 0.1175 \\
\hline No & 197,196 & $3.39(3.15-3.65)$ & $<0.0001$ & \\
\hline Yes & 4102 & $3.07(2.10-4.50)$ & $<0.0001$ & \\
\hline
\end{tabular}

Note 1: the model was adjusted for sex, age, BMI, LDL-C, TC, Scr, ALT, AST, SBP, DBP, drinking, smoking and family history of diabetes Note 2: the model was adjusted for all above variables except the corresponding stratification variable

to be older. Second, taking TyG index as continuous variable and categorical variable respectively, sensitivity analysis and trend test were carried out to improve the reliability of results and avoid the contingency in data analysis. Finally, subgroup analyse and interaction test were conducted to further prove the dependability of the results and identify potential interactions with other variables. This study also had limitations. Firstly, diabetes was diagnosed depending on FPG $\geq 126 \mathrm{mg} / \mathrm{dL}$ or selfreported diabetes, rather than by glycosylated hemoglobin or 2-h oral glucose tolerance test, which was probably underestimated. Secondly, this study did not distinguish between types of diabetes. However, these findings may be more applicable to T2DM, which accounts for approximately $90-95 \%$ of all diabetes cases. Thirdly, data on fasting insulin levels and glycosylated hemoglobin are not available in the database, so it is impossible to compare the accuracy of predicting diabetes risk between TyG and HOMA-IR or glycosylated hemoglobin. Fourthly, as this large cohort study was conducted in China, these findings can not be generalized to other races and certain populations, such as children and pregnant women. Finally, the present report was a secondary analysis on the basis of existing 
database, and although numerous confounding factors had been adjusted, some variables not included in the database, such as physical activity, dietary factors, and lipid-lowering agents, failed to be adjusted. Therefore, potential effects of these residual confounding factors on the results could not be ignored.

\section{Conclusions}

This study manifested that elevated TyG index was independently correlated with increased risk of developing diabetes in Chinese adults. Besides, these findings expand the current knowledge that the TyG index seems to be more sensitive for predicting risk of diabetes in women, younger individuals, and those with normal BMI or SBP. The TyG index may therefore represent a reliable predictor for screening individuals at early diabetes risk, especially in people without high-risk factors such as older age, hypertension and obesity.

\section{Supplementary information}

Supplementary information accompanies this paper at https://doi.org/10. 1186/s12944-020-01403-7.

Additional file 1.

Additional file 2.

Additional file 3.

\section{Abbreviations}

TyG index: Triglyceride-glucose index; BMI: Body mass index; FPG: Fasting plasma glucose; TG: Triglyceride; TC: Total cholesterol; HDL-C: high density lipoprotein cholesterol; LDL-C: low density lipoprotein cholesterol; Scr: Serum creatinine; ALT: Alanine aminotransferase; AST: Aspartate aminotransferase; DBP: Diastolic blood pressure; SBP: Systolic blood pressure; IR: Insulin resistance

\section{Acknowledgements}

Not applicable.

\section{Authors' contributions}

XLL and HJM designed this study. XLL, GLL and TTC conducted data cleaning and statistical analysis. $X L L$ and $J \mathrm{~L}$ made the result interpretation. XLL, GYS and HJM participated in the discussion; XLL drafted the manuscript, and HJM revised it. All authors read and approved the final manuscript.

\section{Funding}

This study was supported by Natural Science Foundation of Hebei Province (No. H2019307108), and Project of Youth Science and Technology of Medical Science Research in Hebei Province (No. 20191706).

\section{Availability of data and materials}

Data can be downloaded from 'DATADRYAD' database (www.Datadryad.org).

\section{Ethics approval and consent to participate}

In the original article [21], Chen, et, al. declared the study was authorized by the Rich Healthcare Group Review Board and complied with the declaration of Helsinki. Considering that the study was retrospective, no participants were required to participate in any part of the study.

\section{Consent for publication}

Not applicable.

\section{Competing interests}

None.

\section{Author details}

'Department of Internal Medicine, Hebei Medical University, Shijiazhuang 050017, Hebei, China. ²Department of Endocrinology and Metabolic Diseases, Hebei General Hospital, Shijiazhuang 050051, Hebei, China. ${ }^{3}$ Department of Cardiology, Xingtai Third Hospital, Xingtai 054000, Hebei, China. ${ }^{4}$ Clinical Medical College, North China University of Science and Technology, Tangshan 063210, Hebei, China. ${ }^{5}$ Hebei Key Laboratory of Metabolic Diseases, Hebei General Hospital, Shijiazhuang 050051, Hebei, China.

Received: 1 September 2020 Accepted: 14 October 2020

Published online: 08 November 2020

\section{References}

1. Yoon $\mathrm{KH}$, Lee $\mathrm{JH}$, Kim JW, et al. Epidemic obesity and type 2 diabetes in Asia. Lancet. 2006;368(9548):1681-8. https://doi.org/10.1016/S01406736(06)69703-1.

2. Global Burden of Metabolic Risk Factors for Chronic Diseases Collaboration. Cardiovascular disease, chronic kidney disease, and diabetes mortality burden of cardiometabolic risk factors from 1980 to 2010: a comparative risk assessment. Lancet Diabetes Endocrinol. 2014;2(8):634-47. https://doi. org/10.1016/S2213-8587(14)70102-0.

3. Seuring $T$, Archangelidi $O$, Suhrcke M. The economic costs of type 2 diabetes: a global systematic review. Pharmacoeconomics. 2015;33(8): 811-31. https://doi.org/10.1007/s40273-015-0268-9.

4. Shaw JE, Sicree RA, Zimmet PZ. Global estimates of the prevalence of diabetes for 2010 and 2030. Diabetes Res Clin Pract. 2010;87(1):4-14. https:// doi.org/10.1016/j.diabres.2009.10.007.

5. Akbari-Fakhrabadi M, Heshmati J, Sepidarkish M, Shidfar F. Effect of sumac (Rhus Coriaria) on blood lipids: a systematic review and meta-analysis. Complement Ther Med. 2018 Oct:40:8-12. https://doi.org/10.1016/j.ctim. 2018.07.001

6. Heshmati J, Sepidarkish M, Namazi N, et al. Impact of dietary calcium supplement on circulating lipoprotein concentrations and Atherogenic indices in overweight and obese individuals: a systematic review. J Diet Suppl. 2019;16(3):357-67. https://doi.org/10.1080/19390211.2018. 1440685.

7. González-Becerra K, Ramos-Lopez O, Barrón-Cabrera E, Riezu-Boj Jl, Milagro Fl, Martínez-López E, Martínez JA. Fatty acids, epigenetic mechanisms and chronic diseases: a systematic review. Lipids Health Dis. 2019:18(1):178. https://doi.org/10.1186/s12944-019-1120-6.

8. Warram JH, Martin BC, Krolewski AS, Soeldner JS, Kahn CR. Slow glucose removal rate and hyperinsulinemia precede the development of type II diabetes in the offspring of diabetic parents. Ann Intern Med. 1990;113(12): 909-15. https://doi.org/10.7326/0003-4819-113-12-909.

9. Defronzo RA. Banting lecture. From the triumvirate to the ominous octet: a new paradigm for the treatment of type 2 diabetes mellitus. Diabetes. 2009; 58(4):773-95. https://doi.org/10.2337/db09-9028.

10. Scheen AJ. Pathophysiology of type 2 diabetes. Acta Clin Belg. 2003;58(6): 335-41. https://doi.org/10.1179/acb.2003.58.6.001.

11. DeFronzo RA, Tobin JD, Andres R. Glucose clamp technique: a method for quantifying insulin secretion and resistance. Am J Phys. 1979;237(3):E214-23. https://doi.org/10.1152/ajpendo.1979.237.3.E214.

12. Simental-Mendía LE, Rodríguez-Morán M, Guerrero-Romero F. The product of fasting glucose and triglycerides as surrogate for identifying insulin resistance in apparently healthy subjects. Metab Syndr Relat Disord. 2008; 6(4):299-304. https://doi.org/10.1089/met.2008.0034.

13. Guerrero-Romero F, Simental-Mendía LE, González-Ortiz M, et al. The product of triglycerides and glucose, a simple measure of insulin sensitivity. Comparison with the euglycemic-hyperinsulinemic clamp. J Clin Endocrinol Metab. 2010;95(7):3347-51. https://doi.org/10.1210/jc.2010-0288.

14. Vasques AC, Novaes FS, de Oliveira MS, et al. TyG index performs better than HOMA in a Brazilian population: a hyperglycemic clamp validated study. Diabetes Res Clin Pract. 2011;93(3):e98-e100. https://doi.org/10.1016/j. diabres.2011.05.030.

15. Guerrero-Romero F, Villalobos-Molina R, Jiménez-Flores JR, et al. Fasting triglycerides and glucose index as a diagnostic test for insulin resistance in young adults. Arch Med Res. 2016:47(5):382-7. https://doi.org/10.1016/j. arcmed.2016.08.012.

16. Mazidi M, Kengne AP, Katsiki N, Mikhailidis DP, Banach M. Lipid accumulation product and triglycerides/glucose index are useful predictors 
of insulin resistance. J Diabetes Complicat. 2018;32(3):266-70. https://doi. org/10.1016/j.jdiacomp.2017.10.007.

17. Zhang $M$, Wang $B$, Liu $Y$, et al. Cumulative increased risk of incident type 2 diabetes mellitus with increasing triglyceride glucose index in normalweight people: the rural Chinese cohort study. Cardiovasc Diabetol. 2017; 16(1):30. https://doi.org/10.1186/s12933-017-0514-x.

18. Lee SH, Kwon HS, Park YM, et al. Predicting the development of diabetes using the product of triglycerides and glucose: the Chungju Metabolic Disease Cohort (CMC) study. PLoS One. 2014;9(2):e90430. Published 2014 Feb 28. https://doi.org/10.1371/journal.pone.0090430.

19. Lee JW, Lim NK, Park HY. The product of fasting plasma glucose and triglycerides improves risk prediction of type 2 diabetes in middle-aged Koreans. BMC Endocr Disord. 2018;18(1):33. https://doi.org/10.1186/ s12902-018-0259-X.

20. Low S, Khoo KCJ, Irwan B, et al. The role of triglyceride glucose index in development of type 2 diabetes mellitus. Diabetes Res Clin Pract. 2018;143: 43-9. https://doi.org/10.1016/j.diabres.2018.06.006.

21. Chen Y, Zhang XP, Yuan J, et al. Association of body mass index and age with incident diabetes in Chinese adults: a population-based cohort study. BMJ Open. 2018;8(9):e021768. https://doi.org/10.1136/ bmjopen-2018-021768.

22. Zhang N, Hu X, Zhang Q, et al. Non-high-density lipoprotein cholesterol: high-density lipoprotein cholesterol ratio is an independent risk factor for diabetes mellitus: results from a population-based cohort study. J Diabetes. 2018;10(9):708-14. https://doi.org/10.1111/1753-0407.12650.

23. Erviti J, Alonso A, Oliva B, et al. Oral bisphosphonates are associated with increased risk of subtrochanteric and diaphyseal fractures in elderly women: a nested case-control study. BMJ Open. 2013;3(1):e002091. https:/doi.org/ 10.1136//bmjopen-2012-002091.

24. Sánchez-García A, Rodríguez-Gutiérrez R, Mancillas-Adame L, et al. Diagnostic accuracy of the triglyceride and glucose index for insulin resistance: a systematic review. Int J Endocrinol. 2020;2020:4678526. https:// doi.org/10.1155/2020/4678526.

25. Navarro-González D, Sánchez-lñigo L, Pastrana-Delgado J, FernándezMontero A, Martinez JA. Triglyceride-glucose index (TyG index) in comparison with fasting plasma glucose improved diabetes prediction in patients with normal fasting glucose: the vascular-metabolic CUN cohort. Prev Med. 2016;86:99-105. https://doi.org/10.1016/j.ypmed.2016.01.022.

26. Athyros VG, Doumas M, Imprialos KP, et al. Diabetes and lipid metabolism. Hormones (Athens). 2018;17(1):61-7. https://doi.org/10.1007/ s42000-018-0014-8.

27. Tangvarasittichai S. Oxidative stress, insulin resistance, dyslipidemia and type 2 diabetes mellitus. World J Diabetes. 2015;6(3):456-80. https://doi.org/10. 4239/wjd.v6.i3.456.

28. Namayandeh SM, Karimi A, Fallahzadeh $\mathrm{H}$, et al. The incidence rate of diabetes mellitus (type II) and its related risk factors: a 10-year longitudinal study of Yazd healthy heart cohort (YHHC). Iran Diabetes Metab Syndr. 2019;13(2):1437-41. https://doi.org/10.1016/j.dsx.2019.02.012.

29. Radzeviciene L, Ostrauskas R. Smoking habits and the risk of type 2 diabetes: a case-control study. Diabetes Metab. 2009;35(3):192-7. https://doi. org/10.1016/j.diabet.2008.11.001.

30. Brath H, Kaser S, Tatschl C, et al. Smoking, alcohol and diabetes (update 2019). Wien Klin Wochenschr. 2019;131(Suppl 1):67-70. https://doi.org/10. 1007/s00508-019-1455-z.

31. Zhang $Y$, Chen $\mathrm{H}$, Lu H, et al. Prevalence and risk of diabetes based on family history in the Shanghai high-risk diabetic screen (SHiDS) study. Diabet Med. 2016;33(12):1705-11. https://doi.org/10.1111/dme.13013.

32. Sánchez-García A, Rodríguez-Gutiérrez R, Mancillas-Adame $L$, et al. Diagnostic natural history of $\beta$-cell adaptation and failure in type 2 diabetes. Mol Asp Med. 2015;42:19-41. https://doi.org/10.1016/j.mam 2014.12.002.

33. Robertson RP, Harmon J, Tran PO, Poitout V. Beta-cell glucose toxicity, lipotoxicity, and chronic oxidative stress in type 2 diabetes. Diabetes. 2004; 53(Suppl 1):S119-24. https://doi.org/10.2337/diabetes.53.2007.s119.

34. Robertson RP, Harmon J, Tran PO, Tanaka Y, Takahashi H. Glucose toxicity in beta-cells: type 2 diabetes, good radicals gone bad, and the glutathione connection. Diabetes. 2003;52(3):581-7. https://doi.org/10. 2337/diabetes.52.3.581.

35. Robertson R, Zhou H, Zhang T, Harmon JS. Chronic oxidative stress as a mechanism for glucose toxicity of the beta cell in type 2 diabetes. Cell
Biochem Biophys. 2007;48(2-3):139-46. https://doi.org/10.1007/s12013-0070026-5.

36. Heshmati J, Golab F, Morvaridzadeh $M$, et al. The effects of curcumin supplementation on oxidative stress, Sirtuin-1 and peroxisome proliferator activated receptor $\gamma$ coactivator 1a gene expression in polycystic ovarian syndrome (PCOS) patients: a randomized placebo-controlled clinical trial. Diabetes Metab Syndr. 2020 Mar-Apr;14(2):77-82. https://doi.org/10.1016/j. dsx.2020.01.002.

37. Sepidarkish M, Akbari-Fakhrabadi M, Daneshzad E, et al. Effect of omega-3 fatty acid plus vitamin E Co-Supplementation on oxidative stress parameters: A systematic review and meta-analysis. Clin Nutr. 2020;39(4): 1019-25. https://doi.org/10.1016/j.clnu.2019.05.004.

38. Damavandi RD, Mousavi SN, Shidfar F, et al. Effects of daily consumption of cashews on oxidative stress and Atherogenic indices in patients with type 2 diabetes: a randomized, Controlled-Feeding Trial. Int J Endocrinol Metab. 2019;17(1):e70744. https://doi.org/10.5812/ijem.70744.

39. Mason TM, Goh T, Tchipashvili V, et al. Prolonged elevation of plasma free fatty acids desensitizes the insulin secretory response to glucose in vivo in rats. Diabetes. 1999:48(3):524-30. https://doi.org/10.2337/ diabetes.48.3.524.

40. Jacqueminet S, Briaud I, Rouault C, Reach G, Poitout V. Inhibition of insulin gene expression by long-term exposure of pancreatic beta cells to palmitate is dependent on the presence of a stimulatory glucose concentration. Metabolism. 2000;49(4):532-6. https://doi.org/10.1016/s00260495(00)80021-9.

41. Maedler K, Spinas GA, Dyntar D, Moritz W, Kaiser N, Donath MY. Distinct effects of saturated and monounsaturated fatty acids on betacell turnover and function. Diabetes. 2001;50(1):69-76. https://doi.org/10. 2337/diabetes.50.1.69

42. Weir GC. Glucolipotoxicity, $\beta$-cells, and diabetes: the emperor has no clothes. Diabetes. 2020;69(3):273-8. https://doi.org/10.2337/db19-0138.

43. Lytrivi M, Castell AL, Poitout V, Cnop M. Recent Insights Into Mechanisms of ß-Cell Lipo- and Glucolipotoxicity in Type 2 Diabetes. J Mol Biol. 2020;432(5): 1514-1534. https://doi.org/10.1016/j.jmb.2019.09.016

44. Fu J, Cui Q, Yang B, et al. The impairment of glucose-stimulated insulin secretion in pancreatic $\beta$-cells caused by prolonged glucotoxicity and lipotoxicity is associated with elevated adaptive antioxidant response. Food Chem Toxicol. 2017;100:161-7. https://doi. org/10.1016/j.fct.2016.12.016.

45. Zhou YP, Grill VE. Long-term exposure of rat pancreatic islets to fatty acids inhibits glucose-induced insulin secretion and biosynthesis through a glucose fatty acid cycle. J Clin Invest. 1994;93(2):870-6. https://doi.org/10. 1172/JCI117042.

46. Zhou YP, Grill V. Long term exposure to fatty acids and ketones inhibits B-cell functions in human pancreatic islets of Langerhans. J Clin Endocrinol Metab. 1995;80(5):1584-90. https://doi.org/10.1210/ jcem.80.5.7745004.

47. Lupi R, Dotta F, Marselli L, et al. Prolonged exposure to free fatty acids has cytostatic and pro-apoptotic effects on human pancreatic islets: evidence that beta-cell death is caspase mediated, partially dependent on ceramide pathway, and BCl-2 regulated. Diabetes. 2002;51(5):1437-42. https://doi.org/ 10.2337/diabetes.51.5.1437.

48. Sawada T, Tsubata H, Hashimoto N, et al. Effects of 6-month eicosapentaenoic acid treatment on postprandial hyperglycemia, hyperlipidemia, insulin secretion ability, and concomitant endothelial dysfunction among newly-diagnosed impaired glucose metabolism patients with coronary artery disease. An open label, single blinded, prospective randomized controlled trial. Cardiovasc Diabetol. 2016;15(1):121. https://doi. org/10.1186/s12933-016-0437-y.

49. Kelley DE, Goodpaster BH, Storlien L. Muscle triglyceride and insulin resistance. Annu Rev Nutr. 2002;22:325-46. https://doi.org/10.1146/annurev. nutr.22.010402.102912.

50. Tripathy D, Almgren P, Tuomi T, Groop L. Contribution of insulin-stimulated glucose uptake and basal hepatic insulin sensitivity to surrogate measures of insulin sensitivity. Diabetes Care. 2004;27(9):2204-10. https://doi.org/10. 2337/diacare.27.9.2204.

51. Vandenbroucke JP, von Elm E, Altman DG, et al. Strengthening the reporting of observational studies in epidemiology (STROBE): explanation and elaboration. Ann Intern Med. 2007;147(8):W163-94. https://doi.org/10. 7326/0003-4819-147-8-200710160-00010-w1. 
52. Greenman Y, Golani N, Gilad S, Yaron M, Limor R, Stern N. Ghrelin secretion is modulated in a nutrient- and gender-specific manner. Clin Endocrinol. 2004;60(3):382-8. https://doi.org/10.1111/j.1365-2265.2004.01993.x.

53. Machann J, Thamer C, Schnoedt B, et al. Age and gender related effects on adipose tissue compartments of subjects with increased risk for type 2 diabetes: a whole body MRI/MRS study. MAGMA. 2005;18(3):128-37. https://doi.org/10.1007/s10334-005-0104-x.

\section{Publisher's Note}

Springer Nature remains neutral with regard to jurisdictional claims in published maps and institutional affiliations.

Ready to submit your research? Choose BMC and benefit from:

- fast, convenient online submission

- thorough peer review by experienced researchers in your field

- rapid publication on acceptance

- support for research data, including large and complex data types

- gold Open Access which fosters wider collaboration and increased citations

- maximum visibility for your research: over $100 \mathrm{M}$ website views per year

At BMC, research is always in progress. 